the masses of clouds came over Adams and Jefferson, I looked until I almost persuaded myself that there were immense icebergs coming from the uplifted frozen North, but the illusion vanished as the summits appeared above the clouds. But what was remarkable is that the next day was pleasant.

"During the last two weeks in November, the average of the thermometer was $16^{\circ}$. The wind was north-west nearly the whole time. The weather was generally very mild, and the number of clear days was much greater than the average."

We may add to this interesting account that the daily telegrams received from the mountain have been full of interest. A temperature of $40^{\circ}$ below zero has not been uncommon, and we may well hope that the efforts of the solitary watchers on the inclement mountain-top will tend to advance the science of which they are such devoted students.

\section{SCIENCE IN VICTORIA}

T OSE who have read the Marquis de Beauvoir's "Voyage round the World" will recollect the high praise with which he speaks of Sir Redmond Barry's prolonged and continuous efforts for the advancement of science in Victoria. His latest good deed in this direction is the aid which he has afforded in the establishment of a School of Mines at Ballarat, which, to use his own words, may now be regarded as "an accomplished fact," since "everything connected with its establishment and maintenance has been thoroughly debated and determined on." The prospectus of the Institution states that "the object sought to be obtained is the combination of the highest scientific with the most practical training for all men engaged in the enterprise of mining in its various branches - whether so engaged as mining managers, engineers, surveyors, mechanists, working miners, directors or promoters of companies;" and, as there is every reason to believe that the school will be supported by the Government, by the several mining boards, and by the general public, we may hope to see it in actual operation in a few months.

We have not space to give a sketch of Sir Redmond Barry's excellent address, further than to remark that he points out the general bearings of chemistry, electricity, geology, steam, \&c., on the progress of mining; and we must content ourselves with the following extract relating to the progress of Science in Australia :-

"We are not," he observes, "even in our time, satisfied to import the discoveries of others, and to invite the man of science and the skilled artisan to direct their operations. Australia can point with a modest satisfaction to the invention of Osborne in photo-lithography, and the test for blood by Dr. Day ; ${ }^{*}$ to the cure for snake-bites by Professor Halford; to the method of removing pyrites, that inveterate enemy of the metallurgist, as well as the native alloys, from gold, and toughening the metal by the use of chlorine gas, by Mr. Miller of the Sydney Mint to the scientific preservation of the meat of our redundant flocks and herds, so largely exported; and also to many others, mention of which would delay us too long."

\section{THE CONTRACTION OF THE EARTH+}

THE phenomena, which were ably presented by the distinguished geologist, Mr. Lesley, to the National Academy of Sciences, and which seem to demonstrate that the outer shell * A full account of Dr. Day's remarkable colour-tests for blood and pus
may be found in Dr. Richardson's Report on Toxicology in the last number may be found in Dr. Richardson's Report

of the Mrom the Proceedings of the American Academy of Arts and Sciences, vol. viii. of the earth has sensibly shrunk, in some directions at least, since its original formation, naturally invite the attention of .phy. sicists to the possible causes of such a result. The most obvious cause of the shrinking of the earth is its cooling. But to shrink two per cent. linearly, which is the amount deduced by Mr.Lesley from the observed geological phenomena, involves a probable cooling of the whole earth of not less than two thousand degrees centigrade, which would require that its original temperature should be higher than would be consistent with the solidity of these shrunk strata.

Another source of change of form, which would produce shrinkages in different directions in different parts of the earth, is to be found in the diminution of oblateness arising from the diminished velocity of rotation upon the axis. Such diminution of the velocity of rotation has several years ago been shown by Mr. Ferrel to be caused by the action of the moon in producing the tides; this is, therefore, a true cause, and it is only necessary to examine how great its amount can be under any circumstances. This is all which is proposed in the present investigation, and the application to facts is reserved for geologists.

It is sufficient, for the present object, to regard the earth as homogeneous. Under this condition Laplace has shown that the time of the earth's rotation could not be less than about one-tenth of a day, which corresponds to a ratio of the axis of the equator to that of the pole, equal to 2.7197 , and an equatorial circumference 94 per cent. greater than the present one. Such is then the amount of shrinking which might have taken place, if any cause could be assigned capable of producing so great a reduction of the earth's velocity. The whole surface of the earth would have been about 130 per cent. larger than at present.

But the only cause at present known which would produce a sensible reduction of the earth's velocity is the lunar action upon the tides. But in this mutral action between the moon and the earth, the common rotation area of the earth and moon must remain unchanged. The question then arises, How great a reduction of the rotation area of the earth would have passed into that of the moon? In this inquiry it may be assumed that the moon revolves in a circular orbit in the plane of the earth's equator.

Now the moon's rotation area is 3.710 times the earth's. But if, in the origin, it had revolved just in contact with this earth, its rotation area would not have been less than 0.480 times the earth's, so that it could not have absorbed a rotation area from the earth greater than 3.236 times the earth's present rotation area, and therefore the earth's rotation area could never have exceeded 4.236 times that which it has at present. But, with the maximum velocity of rotation given by Laplace, the earth's rotation area would have been $37 \frac{1}{2}$ times greater than at present. It can never, therefore, have been reduced to so great an extent by the moon's action on the tides. But since, when the oblateness is small, the rotation area is nearly proportional to the velocity; and the excess of the square of the equatorial above that of the polar axis is nearly proportional to the square of the velocity, this excess may have been originally nearly eighteen times as great as at present, or about $15^{\frac{1}{2}}$ per cent. of the square of the polar axis. This would correspond to a figure of the earth in which the equatorial radius would have been about $2_{2}^{1}$ per cent. greater than at present ; so that it is sufficient to account for the observed phenomenon.

This peculiar form of shrinkage would produce the bighest mountains at the equator, and the tendency of the mountain ranges would then be to assume the direction of the meridian. But nearer the poles the mountains would be less elevated, and would rather tend towards the direction of the parallels of latitude.

It is, next, expedient to consider the mechanical question of the loss of living force in the case of the moon's action upon the waters of the earth, and its effect upon their different motions. In this connection there are problems worthy of the attention of geometers ; such as the relative motions of bodies rotating above the same vertical axis, towards which they are drawn by weights, and acting upon each other through the friction on the axis. For one of the bodies a rotating wheel may be substituted. There is also the case of two planets revolving about a primary, and acting upon each other through some form of friction.

In this way it will be seen that the planet or satellite once formed is constantly removed from the primary, and that planets tend to approach each other. It is interesting to consider whether this may not be one of the actual problems of nature.

B. PeIRCe 